\title{
Grußwort von Dr. Boštjan Žeǩs, Berater des slowenischen Staatspräsidenten
}

Sehr geehrte Damen und Herren, sehr geehrte Veranstalter des Treffens und der Aufstellung der Gedenktafel, liebe Geschichtsvereinsmitglieder und Museumsvertreter, liebe Gäste,

zunächst möchte ich mich dafür bedanken, dass ich eingeladen wurde, an diesem Treffen und der Enthüllung der Gedenktafel zu Ehren Primož Trubars, unseres großen Reformatoren und Pionieres des geschriebenen Wortes in slowenischer Sprache, teilzunehmen. Es ist mir eine große Ehre, heute hier sein zu dürfen und mich gemeinsam mit Ihnen an die beiden ersten gedruckten Bücher in slowenischer Sprache zu erinnern - den Katechismus und das Abecedarium. Beide sind Werke Primož Trubars und wurden im Jahre 1550 genau hier gedruckt.

Das war der Anfang, der reiche Früchte hervorbrachte. Allein Trubars Opus umfasst mehr als 8000 gedruckte Seiten; an dieser Stelle sei nur die Übersetzung des Katechismus von Johannes Brenz erwähnt. Trubars Schüler und Mitarbeiter setzten die Arbeit fort; den Höhepunkt erreichte 1584 Jurij Dalmatin mit der Übersetzung der gesamten Heiligen Schrift. Dabei dürfen wir nicht vergessen, dass damals auch das Schulsystem eingeführt wurde.

Später herrschte bei uns der katholische Glaube vor, während die Protestanten nur in einem Teil Sloweniens verblieben. Noch lange wurde hingegen die protestantische Bibel verwendet, es blieben das Schulwesen und der Wunsch zu lernen, es blieb die Erinnerung, und es blieb auch etwas von der protestantischen Ethik. Auf dieser Basis sind wir durch die Jahrhunderte vorangeschritten. Das Buch, die Kultur und das Lernen waren für uns stets am wichtigsten. Im Jahre 1919 haben wir die erste slowenische Universität bekommen, kurz vor dem Zweiten Weltkrieg noch die Slowenische Akademie der Wissenschaften und Künste, die Nationalbibliothek und andere nationale Institutionen. All das haben wir ohne eigenen Staat, ohne eigene politische Macht erreicht. Am Ende, als wir all das geregelt hatten, bekamen wir im Jahre 1991 auch noch unseren eigenen Staat. Da die Reformation für uns so wichtig war, feiert auch Slowenien in diesem Jahr das 500. Reformationsjubiläum mit mehreren Gedenkveranstaltungen, die von einem Ausschuss unter der Leitung des Staatspräsidenten koordiniert werden.

Unsere Entwicklung war beachtenswert, doch gab es für das kleine Volk, eingezwängt zwischen den größeren romanischen, germanischen, finno-ugrischen 
und slawischen Völkern, gar keine andere Möglichkeit. Alles beruhte auf der Kultur, und das Ganze begann vor fast 500 Jahren hier bei Ihnen in Schwäbisch Hall.

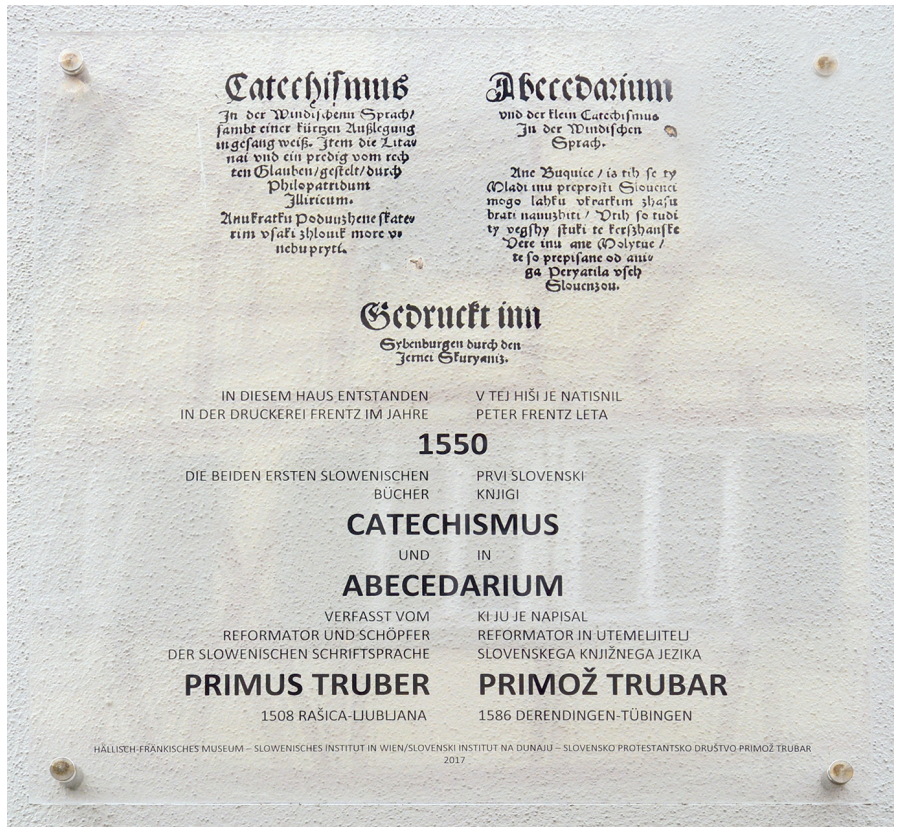

